脳動静脈奇形治療のエビデンスとリアルワールド

高木 康志

徳島大学脳神経外科

\title{
Real-world Evidence in the Surgical Treatment of Brain Arteriovenous Malformation
}

\author{
Yasushi Takagi, M.D., Ph.D.
}

Department of Neurosurgery, Graduate School of Biomedical Sciences, Tokushima University

Since the results of the ARUBA trial and Scottish Audit were published, surgical treatment of brain arteriovenous malformation (AVM) has entered a new era. Here, we summarize the results of the ARUBA trial and Scottish Audit and review criticisms against these studies. Recently, a statement about AVM was published by the American Heart Association (AHA)/American Stroke Association(ASA). Finally, current and future statuses of AVM surgery are mentioned based on the reviewed cases.

(Received November 7, 2018; accepted November 15, 2018)

Key words : arteriovenous malformation, American Heart Association(AHA)/American Stroke Association (ASA) statement, surgical treatment

Jpn J Neurosurg（Tokyo）28:142-148, 2019

\section{はじめに}

未破裂脳動静脈奇形（arteriovenous malformation： AVM）に対する治療は，2014 年の ARUBA trial（A Randomized Trial of Unruptured Brain Arteriovenous Malformations）と Scottish Audit の発表以来，新たな転機を迎 えた ${ }^{113)}$. 本稿ではこれらの臨床研究の内容を確認し, 明らかになった点と本研究の問題点を検討する。また, 2017 年には American Heart Association (AHA)/American Stroke Association (ASA) の scientific statement が発表さ れた ${ }^{6)}$. 現時点での AVM に対する考え方を，最近の報告 をもとに解説する ${ }^{2224)}$ 。また，著者が在籍した施設での AVM に対する治療について報告し，さらには，現時点で 可能な安全な AVM 摘出術について症例をもとに紹介す る。

\section{The ARUBA trial}

ARUBA trial は 2006 年 10 月に登録が開始された ${ }^{13)}$. 18 歳以上の未破裂 AVM の患者をランダム化し，内科的 治療または何らかの侵襲的治療（外科的摘出術，放射線 治療，血管内治療）を行う群に割り当てられた。主要評 価項目はすべての死亡または症候性脳卒中である。 2013 年 4 月の中間解析において, 計 223 例, 平均 33.3 力月の 追跡が行われた。結果的に 223 例のうち，侵襲的治療が 行わ机た群は 114 例, 内科的治療が行われた群が 109 例 であった。主要評価項目である死亡または脳卒中は asrandomized analysis で内科的治療群 11 例 $(10.1 \%)$, 侵襲 的治療群では 35 例 $(30.7 \%)$ であった。このように中間 解析では未破裂脳動静脈奇形の治療において内科的治療 が侵襲的治療に優ることが示された ${ }^{13)}$. 
Table 1 Summary of studies examining surgical and radiosurgical outcomes in ARUBA-eligible patients

\begin{tabular}{l|c|c|c|c|c|c}
\hline \multicolumn{1}{c|}{ Authors } & Patients & $\begin{array}{c}\text { Surgery w/wo } \\
\text { embolization (\%) }\end{array}$ & $\begin{array}{c}\text { Radiosurgery } \\
\text { w/wo } \\
\text { embolization }(\%)\end{array}$ & $\begin{array}{c}\text { Combination } \\
\text { treatment }(\%)\end{array}$ & $\begin{array}{c}\text { Stroke or death } \\
(\%)\end{array}$ & $\begin{array}{c}\text { mRS scores } \geq 2 \\
(\%)\end{array}$ \\
\hline Nerva et al & 61 & $31(50.8 \%)$ & $30(49.2 \%)$ & 0 & Not reported & $8(13.1 \%)$ \\
Rutledge et al & 74 & $43(58.1 \%)$ & $15(20.3 \%)$ & $2(2.7 \%)$ & $9(12.2 \%)$ & $8(10.8 \%)$ \\
Javadpour et al & 34 & $34(100 \%)$ & 0 & 0 & 0 & $2(5.9 \%)$ \\
Schramm et al & 104 & $104(100 \%)$ & 0 & 0 & $45(7.7 \%)$ & $10(10.4 \%) \dagger$ \\
Ding et al & 509 & 0 & $509(100 \%)$ & 0 & $20(11.5 \%) *$ & Not reported \\
Pollock et al & 174 & 0 & $174(100 \%)$ & 0 & $(9.2 \%)$ \\
\hline
\end{tabular}

${ }^{\dagger}$ Out of 96 patients with evaluable mRS scores, ${ }^{\star}$ At $10^{-}$year follow-up

\section{Scottish Audit}

Scottish Audit of Intracranial Vascular Malformations は 英国スコットランドで行われた 16 歳以上の AVM に対す るコホート研究である ${ }^{1)}$. 保存的治療群 101 例と侵襲的 治療群 103 例において, 主要評価項目を死亡, 二次評価 項目を臨床的悪化とし，12 年までの経過観察期間で hazard ratio が 0.59 （95\% CI 0.35～0.99）で保存的治療群で よりリスクが少なかったと報告している1).

\section{ARUBA trial と Scottish Audit の問題点}

ARUBA trial と Scottish Auditの結果は未破裂 AVM に 対する安易な外科的介入に対して警鐘を鳴らすものと なった1)13). Magro ら ${ }^{12)}$ は, 2006〜2015 年にかけて ARUBA trial について書かれた論文を review し，この研 究に対するコメントや批判をまとめている。この中では study design として評価項目の不備, inclusion criteriaの 不均一性, 治療の標準化の不在, 内科的治療に有利であ るデザインが指摘されている。また, 登録外症例の多さ, Spetzler-Martin grade I 〜 II の直達手術症例の少なさと, high grade 症例に対する血管内治療または放射線治療の みの症例の多さも批判を受けている.さらに subgroup 解 析の不在, follow-up 期間の短さ, 各治療方法における詳 細な解析の不在も指摘されている。 また, ARUBA trialの inclusion criteria に合致する症例の外科的治療の成績に ついても，直達手術および定位放射線治療を数多く経験 した多くの施設より報告された年5)7)9) 11)14)16)17)19).

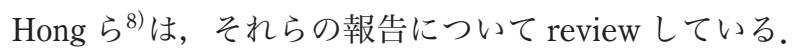
その中で, ARUBA trialの primary endpoint であった stroke or death は 0〜13.1\%，さらには modified Rankin Scale (mRS) が 2 以上であった率は 5.9〜 13.1\%であると している $(\text { Table 1 })^{8)}$. Wong ら ${ }^{26)}$ は, 同様に ARUBA trial に合致した症例での治療成績について報告している.
$\mathrm{mRS}$ が 1 以上の永続する何らかの神経学的後遺症は 16.1\%で生じ, Spetzler-Martin grade I， II では永続する 後遺症は $3.4 \%$ で生じたとしている。また，SpetzlerMartin grade I, II については, これまでに数多くの直達 手術の治療成績を発表してきた UCSF Brain AVM study projectでは morbidity は 2.4\%, Macquarie University では $0.7 \%$ と報告している ${ }^{14)}{ }^{17)}$ 。このように Spetzler-Martin grade が低い症例については，外科的治療を数多く手が けてきた施設からは，ARUBA trial と比較して良好な治 療成績が報告されている。また，最近，欧米の AVM 治 療のエキスパートの意見が European consensus conference として報告された3)。この中では, 現在未破裂 AVM は治療すべきかという命題が提示され，具体的な状況ご とに意見がまとめられた $(\text { Table } 2)^{3)}$ 。総論としてエキス パートたちの意見は，安全に治療できる症例は治療すべ きであるということであった。参加者全員が ARUBA trial の結果をすべての AVM に当てはめることはできな いと断言した。出血率を上げる要素としては，動脈瘤， 静脈パターン, 部位が指摘された。また, eloquence, 若 年, 深部フィーダー, 深在性のいずれの症例においても, 症例により治療適応になり得るとの意見が提示された。 さらに, 高齢（65 歳以上）と大きなナイダスは手術適応 とはなりにくいとの意見が多数で, diffuse ナイダスは治 療適応を決定する際に問題となるが定義の難しさを指摘 されている. 加えて, 今後の臨床研究としては，新しい ランダム化試験よりはレジストリー研究のほうが望まし いとしている3). また，新しいレジストリーについても 提案されている3)4)15)18).

\section{AHA/ASA の scientific statement}

このような状況の中で，2017 年に AHA/ASA の scientific statement が発表された ${ }^{6)}$ 。この中で, 未破裂 AVM の 治療としては以下のように述べられている。(1)2つの臨 
Table 2 General questions addressed for the management of uBAVMs

- Is your experience in accordance with the main message of the ARUBA Study, i. e., that unruptured AVMs have a better prognosis if not treated?

- Do you think that some unruptured AVMs have to be treated?

- Do you think that there are elements that increase the risk of bleeding in an unruptured AVM?

- Is eloquence a contraindication to treatment?

- Is young age a contraindication to treatment?

- Is old age ( $>65$ years) a contraindication to treatment?

- Is small size a contraindication to treatment?

- Is large size a contraindication to treatment?

- Are deep feeders a contraindication to treatment?

- Are deep ${ }^{-}$seated malformations a contraindication to treatment?

- Is diffuseness a contraindication to treatment?

- Should a new randomized trial be proposed or a registry can be better?

床研究（ARUBA trial と Scottish Audit）がより非侵襲的 なアプローチを支持している。しかし 2 つの大きな limitation が結論を弱めている，(2)こ机らの 2 つの臨床研究 は follow-up 期間が短く, 小児例を含まず一般化するこ とが困難である，(3)合併症率が予想されたより高い。ま た，破裂 AVM については，11大きさが小さく，表在性 AVM は緊急手術で摘出可能である。より大きく, 深在性 のAVM は 2〜6 週間摘出術を保留したほうがよいとし， (2)破裂 AVM の緊急手術は morbidity や mortalityの増加に 関与する可能性がある, (3)high Spetzler-Martin grade の AVM はすでに神経学的障害がある場合でも, 症状の悪 化の可能性を考慮に入れて治療する必要がある, と述べ ている．以上のことから総論として，未破裂 AVM に関 しては，治療リスクと治療法，余命を慎重に考慮したう えで治療方針を決定するべきであるとし，破裂 AVM で は治療リスクと利点を慎重に考慮しながら治療方針と治 療の組み合わせを検討すべきであるとしている ${ }^{6)}$ 。この ような状況の中で，筆者は安全な外科的治療が行われる ことと未破裂の症例では合併症率を低く外科治療を行う ことが重要であると考えている.

\section{AVM 治療のリアルワールド}

筆者が所属した京都大学医学部附属病院では, 紹介患 者は京都府内のみならず大阪府や滋賀県, または他府県 の関連施設から紹介されている。 また，保存的治療の症 例も検査入院となっていた。すなわち都市部の紹介病院 での状況となる。2008年 1月～2017年 10月までの間に, 計 102 例の症例が入院し, 62 例が外科的治療を受けてい た. Spetzler-Martin grade I, II では, 91\%の症例に対し て外科的治療が行われた。 また, Spetzler-Martin grade III，IVでは，46\%の症例に対して外科的治療が行われ
た。Grade II では非出血発症例では放射線治療が選択さ れていた。 また, 最近の症例では, 手術を含む治療が減 少し，放射線治療を含む症例が増加している傾向があっ た。一方, 筆者が現在所属している徳島大学病院脳神経 外科では紹介患者は徳島県全域と香川県, 愛媛県, 高知 県の一部の関連施設から紹介されていた。また，入院症 例は外科的治療が行われていた。これは，地方の中核都 市病院での状況であると考えられる。さらには，徳島大 学病院には脳卒中センターがあり, 脳卒中センターには 年間約 300 例が入院となっており, 年間約 60 例の脳出血 の症例が入院となっていた。 2008 年 1 月〜 2017 年 10 月 までの間に, 徳島大学脳神経外科では 34 症例が外科的 治療を行っていた。出血発症例は 25 例, 非出血発症例は 9例であった. Spetzler-Martin grade I, II は25例であっ た. AVM 症例の入院経路を調べてみると, 外来経由が 46\%, 脳卒中センター経由が $54 \%$ であった。脳卒中セン

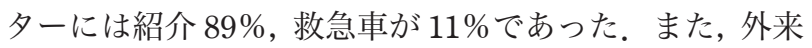
経由は $100 \%$ 紹介症例であった。

\section{AVM の外科治療の実際}

われわれはこれまでも，より安全に手術を行うために さまざまな工夫を(てきた ${ }^{720) \sim 23)}$ ．また，多くの施設か らも安全に手術を行うために，さまざまなテクニックが 報告されてきた。

まず，今では基本となっているが手術の準備として， non-sticking bipolar coagulator の準備が必要であると考 えている. Non-sticking を謳つた鑷子はいくつかの会社 から発売されている，主なものとしては鑷子内に管腔構 造をもつ IsoCool forceps や Spetzler Malis forceps（Codman Neuro, Depuy Synthes, Raynham, MA), VersaTru (Integra LifeSciences, Plainsboro, NJ) がある。また, 

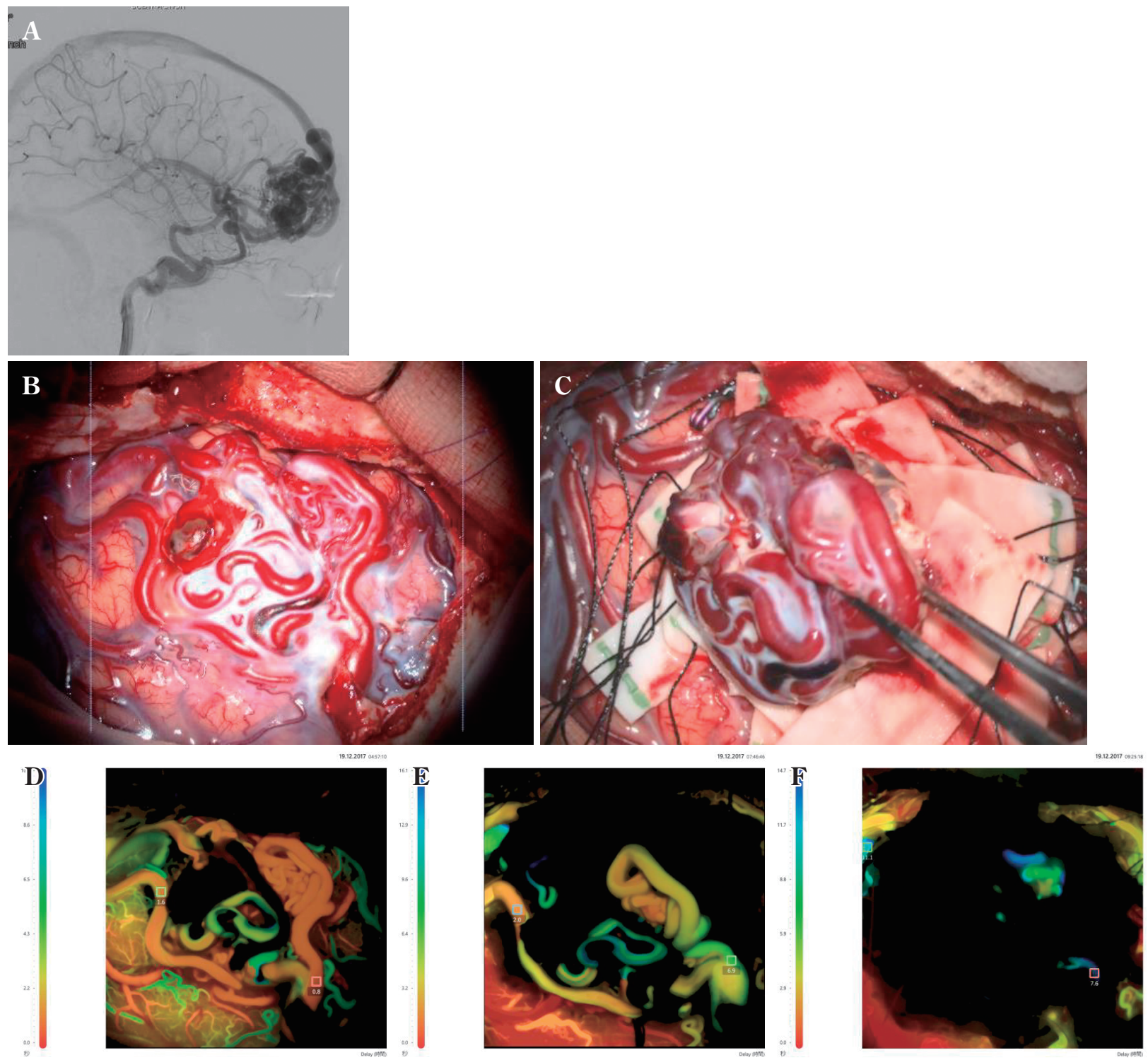

A : Left internal carotid angiogram.

Fig. 1 19-year-old male

B , C : Intraoperative view of AVM nidus. Pre-dissection $(\mathbf{B})$ and nidus removal $(\mathbf{C})$.

D-F : Intraoperative ICG videoangiography. Flow800 images of the nidus. Pre-dissection (D), during dissection (E), and post-dissection ( $\mathbf{F})$.

Silverslim forceps (Nova Surgical Innovations, Temecula, CA）も non-stick forceps である。これらの鑷子の登場に より, 白質内の fragile な血管が鑷子に焦げ付いて引き抜 けることが少なくなり，止血に難渋することが少なく なった ${ }^{2122)}$ 。また, 術中にナイダスやドレーナーの血流 評価を行うことも必要である。これには, hybrid operating room においては術中血管撮影が利用できる。また, 脳表のナイダスやドレーナーの評価には ICG（indocyanine green) videoangiography が重要である ${ }^{23)}$. ICG videoangiography や術中 DSA を用いるとナイダス血流の減
少が確認でき，術前計画で脳表でとらえることのできる フィーダーが処理されれば，軟膜下のナイダス剝離に 移っていく。ナイダス周囲の細かい血管を確認し丁寧に 燒灼しながら剝離を続ける。ナイダスの血流が減少すれ ばナイダスは柔らかくなり，ナイダスの底部も剝離でき るようになる。後頭葉の AVM など術野の対側にフィー ダーが存在するときには, 最近の Onyx によるナイダス 塞栓術は非常に有用である。ただし，ナイダスが堅くな りナイダスの底部の止血が難しくなることには留意して おく必要がある。最終的にドレーナーの順行性血流が消 

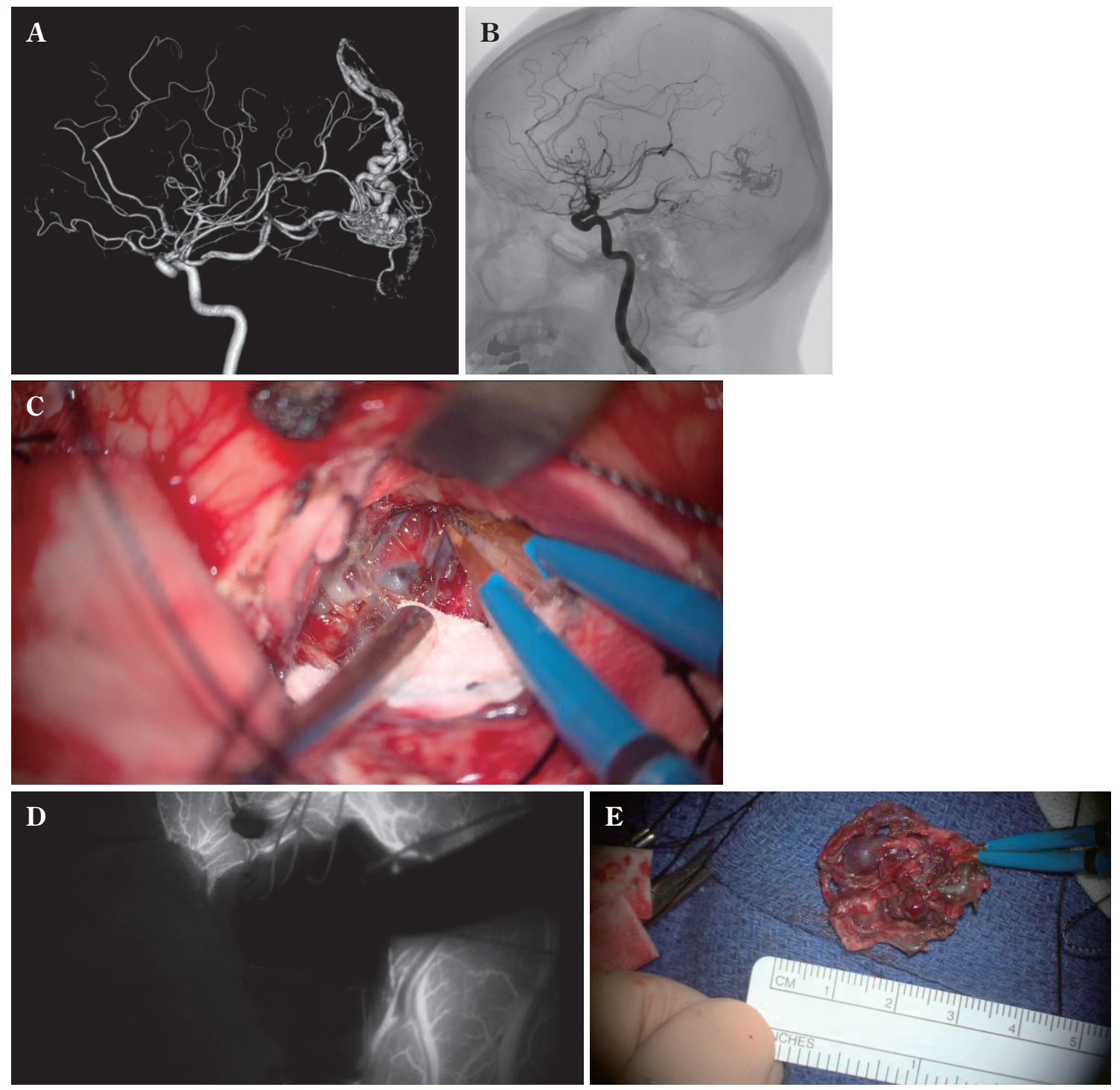

Fig. 2 50-year-old male

A, B : Left internal carotid angiogram. Pre-embolization (A) and postoperative embolization (B). $\mathbf{C}-\mathbf{E}$ : Intraoperative view of AVM nidus. Dissection of the nidus ( C ). Intraoperative ICG videoangiography after dissection of the nidus (D). Nidus removal (E).

失したことを確認し，ナイダスを摘出する.

\section{1 症例 1}

19 歳男性，未破裂 AVM. 左前頭葉 Spetzler-Martin Grade II の症例である。術前にコイルによる feeder 塞栓 術を行ったうえで摘出術を行った。まずはfeederをク リップし, ナイダスの血流を減少させてのちにナイダス 摘出を行った. ICG videoangiographyでは, Flow800(Carl Zeiss Meditec, Oberkochen, Germany）にてナイダスの血 流が徐々に減少していくのがカラーマップにて確認でき る (Fig. 1).

\section{2 症例 2}

50 歳, 未破裂 AVM. 左後頭葉 Spetzler-Martin Grade IIIの症例である. Onyx でナイダス塞栓術を行ったうえ でナイダス摘出術を行った。術前塞栓術で, アプローチ 側の対側にあるfeeder とナイダスを塞栓してあるために 出血コントロールが容易であった。 ICG videoangiographyでナイダスの血流が消失していることを確認のう え, ナイダスを摘出した (Fig. 2). 


\section{今後の展望}

ARUBA trial と Scottish Audit の結果, 特に未破裂 AVM を中心に以前と比較して morbidity の高い治療は認めら れなくなりつつある。いつも述べていることだが，私た ち脳神経外科医は, Spetzler-Martin grade の低い AVM を morbidity なく確実に治療していくことが重要であ $ろ^{2022)}$. Spetzler-Martin gradeの高い症例に対しては, その中で morbidity が少なく治療できる症例を選択し治 療を行うとともに，再出血を繰り返す症例など予後が悪 い難治性の症例に対し新たな治療を開発していく必要も 求められると考えている.

\section{謝 辞}

今回の論文には京都大学医学部附属病院と徳島大学病院お よびその関連施設の症例が含まれています。症例に関わられ た京都大学 宮本 享教授, 徳島大学病院 永廣信治院長, 川崎医科大学 宇野昌明教授, また徳島大学関連病院の先生 方に深謝申し上げます。

著者は日本脳神経外科学会への COI 自己申告の登録を完了 しています。本論文に関して開示すべき COI はありません，

\section{文 献}

1) Al-Shahi Salman R, White PM, Counsell CE, du Plessis J, van Beijnum J, Josephson CB, Wilkinson T, Wedderburn CJ, Chandy Z, St George EJ, Sellar RJ, Warlow CP ; Scottish Audit of Intracranial Vascular Malformations Collaborators: Outcome after conservative management or intervention for unruptured brain arteriovenous malformations. JAMA 311: 1661-1669, 2014.

2) Amin-Hanjani $S:$ ARUBA results are not applicable to all patients with arteriovenous malformation. Stroke 45: 1539-1540, 2014.

3) Cenzato M, Boccardi E, Beghi E, Vajkoczy P, Szikora I, Motti E, Regli L, Raabe A, Eliava S, Gruber A, Meling TR, Niemela M, Pasqualin A, Golanov A, Karlsson B, Kemeny A, Liscak R, Lippitz B, Radatz M, La Camera A, Chapot R, Islak C, Spelle L, Debernardi A, Agostoni E, Revay M, Morgan MK : European consensus conference on unruptured brain AVMs treatment (Supported by EANS, ESMINT, EGKS, and SINCH). Acta Neurochir (Wien) 159: 10591064, 2017.

4) Darsaut TE, Magro E, Gentric JC, Batista AL, Chaalala C, Roberge D, Bojanowski MW, Weill A, Roy D, Raymond J : Treatment of Brain AVMs (TOBAS) : study protocol for a pragmatic randomized controlled trial. Trials $\mathbf{6}: 497,2015$.

5) Ding D, Yen CP, Xu Z, Starke RM, Sheehan JP : Radiosurgery for low-grade intracranial arteriovenous malformations. $J$ Neurosurg 121: 457-467, 2014.

6) Derdeyn CP, Zipfel GJ, Albuquerque FC, Cooke DL, Feldmann E, Sheehan JP, Torner JC ; American Heart Association Stroke Council: Management of brain arteriovenous malformations : A scientific statement for healthcare professionals from the American Heart Association/American
Stroke Association. Stroke 48: e200-e224, 2017.

7) Hashimoto N, Nozaki K, Takagi Y, Kikuta K, Mikuni N : Surgery of cerebral arteriovenous malformations. Neurosurgery 61 (1 Suppl) : 375-387; discussion 387-389, 2007.

8) Hong CS, Peterson EC, Ding D, Sur S, Hasan D, Dumont AS, Chalouhi N, Jabbour P, Starke RM : Intervention for a randomized trial of unruptured brain arteriovenous malformations (ARUBA) -Eligible patients: An evidence-based review. Clin Neurol Neurosurg 150: 133-138, 2016.

9) Kano H, Lunsford LD, Flickinger JC, Yang HC, Flannery TJ, Awan NR, Niranjan A, Novotny J Jr, Kondziolka D : Stereotactic radiosurgery for arteriovenous malformations, Part 1: management of Spetzler-Martin Grade I and II arteriovenous malformations. J Neurosurg 116: 11-20, 2012.

10) Lawton MT: The role of AVM microsurgery in the aftermath of A Randomized Trial of Unruptured Brain Arteriovenous Malformations. AJNR Am J Neuroradiol 36:617619, 2015.

11) Lawton MT, Abla AA: Management of brain arteriovenous malformations. Lancet $383: 1634-1635$, 2014. (Letter)

12) Magro E, Gentric JC, Darsaut TE, Ziegler D, Msi, Bojanowski MW, Raymond J : Responses to ARUBA : a systematic review and critical analysis for the design of future arteriovenous malformation trials. J Neurosurg 129:486494, 2017.

13) Mohr JP, Parides MK, Stapf C, Moquete E, Moy CS, Overbey JR, Al-Shahi Salman R, Vicaut E, Young WL, Houdart E, Cordonnier C, Stefani MA, Hartmann A, von Kummer R, Biondi A, Berkefeld J, Klijn CJ, Harkness K, Libman R, Barreau X, Moskowitz AJ ; international ARUBA investigators: Medical management with or without interventional therapy for unruptured brain arteriovenous malformations (ARUBA) : a multicentre, non-blinded, randomised trial. Lancet 383: 614-621, 2014.

14) Morgan MK, Rochford AM, Tsahtsarlis A, Little N, Faulder $\mathrm{KC}$ : Surgical risks associated with the management of Grade I and II brain arteriovenous malformations. Neurosurgery 61 (1 Suppl) : 417-422 ; discussion 422424, 2007.

15) Pierot L, Fiehler J, Cognard C, Söderman M, Spelle L : Will a randomized trial of unruptured brain arteriovenous malformations change our clinical practice? AJNR AmJ Neuroradiol 35 : 416-417, 2014.

16) Pollock BE, Link MJ, Brown RD : The risk of stroke or clinical impairment after stereotactic radiosurgery for ARUBA-eligible patients. Stroke 44: 437-441, 2013.

17) Potts MB, Lau D, Abla AA, Kim H, Young WL, Lawton MT ; UCSF Brain AVM Study Project: Current surgical results with low-grade brain arteriovenous malformations. $J$ Neurosurg 122: 912-920, 2015.

18) Proust F, Roche PH, Meling TR: Does ARUBA study improve our knowledge as regards the management of unruptured brain arteriovenous malformations? Neurochirurgie $60: 2-4,2014$.

19) Rutledge WC, Abla AA, Nelson J, Halbach VV, Kim H, Lawton MT: Treatment and outcomes of ARUBA-eligible patients with unruptured brain arteriovenous malformations at a single institution. Neurosurg Focus 37: E8, 2014.

20）高木康志：術前 $3 \mathrm{D}$ シミュレーションと術中血流評価に より安全に摘出できた eloquent area 近傍に存在する非表 在性脳動脈静脈奇形の 1 例. 脳外誌 $25: 259-263,2016$. 
21）高木康志，橋本信夫：脳動静脈奇形手術の基本手技．No Shinkei Geka 34:1207-1214, 2006.

22）高木康志：AVM に対する治療選択と外科治療の実際。脳 外誌 26:117-124, 2016.

23) Takagi Y, Sawamura K, Hashimoto N, Miyamoto S : Evaluation of serial intraoperative surgical microscope-integrated intraoperative near-infrared indocyanine green videoangiography in patients with cerebral arteriovenous malformations. Neurosurgery $\mathbf{7 0}$ (1 Suppl Operative) : 34-42; discussion $42-43,2012$.
24）辻 篤司，中澤拓也，野崎和彦：ARUBA study 後の脳動 静脈奇形の治療。No Shinkei Geka 44:269-281, 2016.

25) Yen CP, Ding D, Cheng CH, Starke RM, Shaffrey M, Sheehan $\mathrm{J}$ : Gamma Knife surgery for incidental cerebral arteriovenous malformations. J Neurosurg 121: 1015-1021, 2014.

26) Wong J, Slomovic A, Ibrahim G, Radovanovic I, Tymianski M : Microsurgery for ARUBA Trial (A Randomized Trial of Unruptured Brain Arteriovenous Malformation) -Eligible Unruptured Brain Arteriovenous Malformations. Stroke 48: 136-144, 2017.

要

旨

脳動静脈奇形治療のエビデンスとリアルワールド

高木 康志

未破裂脳動静脈奇形（arteriovenous malformation：AVM）に対する治療は, 2014 年の ARUBA trial と Scottish Audit の発表以来，新たな転機を迎えている．また，2017 年には AHA/ASA の scientific statement が発表された. 現時点での脳動静脈奇形に対する考え方を, 最近の報告をもとに解説する. また, 著者が在籍した施設での AVM に対する治療について報告し, 現時点で可能な安全な AVM 摘出 術について症例をもとに紹介する.

脳外誌 $28 ： 142-148,2019$ 